\title{
Fontan hemodynamics from 100 patient-specific cardiac magnetic resonance studies: A computational fluid dynamics analysis
}

\author{
Christopher M. Haggerty, PhD, ${ }^{\mathrm{a}}$ Maria Restrepo, BS, ${ }^{\mathrm{a}}$ Elaine Tang, BEng, ${ }^{\mathrm{a}}$ Diane A. de Zélicourt, PhD, ${ }^{\mathrm{a}, \mathrm{b}}$ \\ Kartik S. Sundareswaran, $\mathrm{PhD},{ }^{\mathrm{a}}$ Lucia Mirabella, $\mathrm{PhD},{ }^{\mathrm{a}}$ James Bethel, $\mathrm{PhD}$, \\ Kevin K. Whitehead, MD, PhD, ${ }^{\mathrm{d}}$ Mark A. Fogel, MD, ${ }^{\mathrm{d}}$ and Ajit P. Yoganathan, $\mathrm{PhD}^{\mathrm{a}}$
}

\begin{abstract}
Objectives: This study sought to quantify average hemodynamic metrics of the Fontan connection as reference for future investigations, compare connection types (intra-atrial vs extracardiac), and identify functional correlates using computational fluid dynamics in a large patient-specific cohort. Fontan hemodynamics, particularly power losses, are hypothesized to vary considerably among patients with a single ventricle and adversely affect systemic hemodynamics and ventricular function if suboptimal.
\end{abstract}

\begin{abstract}
Methods: Fontan connection models were created from cardiac magnetic resonance scans for 100 patients. Phase velocity cardiac magnetic resonance in the aorta, vena cavae, and pulmonary arteries was used to prescribe patient-specific time-averaged flow boundary conditions for computational fluid dynamics with a customized, validated solver. Comparison with 4-dimensional cardiac magnetic resonance velocity data from selected patients was used to provide additional verification of simulations. Indexed Fontan power loss, connection resistance, and hepatic flow distribution were quantified and correlated with systemic patient characteristics.
\end{abstract}

Results: Indexed power loss varied by 2 orders of magnitude, whereas, on average, Fontan resistance was $15 \%$ to $20 \%$ of published values of pulmonary vascular resistance in single ventricles. A significant inverse relationship was observed between indexed power loss and both systemic venous flow and cardiac index. Comparison by connection type showed no differences between intra-atrial and extracardiac connections. Instead, the least efficient connections revealed adverse consequences from localized Fontan pathway stenosis.

Conclusions: Fontan power loss varies from patient to patient, and elevated levels are correlated with lower systemic flow and cardiac index. Fontan connection type does not influence hemodynamic efficiency, but an undersized or stenosed Fontan pathway or pulmonary arteries can be highly dissipative. (J Thorac Cardiovasc Surg 2014;148:1481-9)

The Fontan procedure is the palliative strategy used to treat single ventricle lesions, ${ }^{1}$ with the staged total cavopulmonary connection (TCPC) being the predominant modern approach. Operative mortality is low, ${ }^{2}$ but gradual attrition persists. ${ }^{3}$ The TCPC is known to mediate an adverse and "paradoxical" hemodynamic environment, ${ }^{4}$ and TCPC power loss has been implicated for contributing to some longterm complications, such as poor exercise tolerance. ${ }^{5}$

\footnotetext{
From the Wallace H. Coulter Department of Biomedical Engineering, ${ }^{\text {a }}$ Georgia Institute of Technology \& Emory University, Atlanta, Ga; Interface Group, ${ }^{\mathrm{b}}$ Institute of Physiology, University of Zürich, Zürich, Switzerland; Westat, Inc, ${ }^{c}$ Rockville, Md; and Division of Cardiology, ${ }^{\mathrm{d}}$ Children's Hospital of Philadelphia, Philadelphia, $\mathrm{Pa}$.

This study was supported by the National Heart, Lung, and Blood Institute Grants R01HL67622 and R01HL098252, and a Pre-Doctoral Fellowship (10PRE3720002) from the American Heart Association.

Disclosures: Kartik S. Sundareswaran reports equity ownership in Thoratec. Mark A. Fogel reports grant support from Siemens. All other authors have nothing to disclose with regard to commercial support.

Received for publication Aug 20, 2013; revisions received Oct 27, 2013; accepted for publication Nov 15, 2013; available ahead of print Feb 6, 2014.

Address for reprints: Ajit P. Yoganathan, PhD, Wallace H. Coulter Department of Biomedical Engineering, Georgia Institute of Technology \& Emory University, 387 Technology Circle, Suite 232, Atlanta, GA 30313-2412 (E-mail: ajit. yoganathan@bme.gatech.edu).

$0022-5223 / \$ 36.00$

Copyright (c) 2014 by The American Association for Thoracic Surgery

http://dx.doi.org/10.1016/j.jtcvs.2013.11.060
}

For these reasons, the TCPC has been the focus of a large body of translational research, ${ }^{6}$ with the majority of these studies using medical imaging or computational fluid dynamics $(\mathrm{CFD})^{5,7-12}$ to characterize TCPC hemodynamics at a patient-specific level. CFD in particular has been widely used on the basis of its ability to parametrically evaluate the effects of individual variables on hemodynamic end points of interest with excellent spatial resolution. Collectively, this work has provided significant insights into the tight coupling between the connection geometry and the resulting fluid mechanics, such as the effects of caval offset ${ }^{13}$ or Fontan anastomosis design, ${ }^{14}$ and general differences between extracardiac and lateral tunnel connections. ${ }^{11}$ However, these studies have relied on small sample sizes, resulting in a poor understanding of average power loss magnitudes at a population level or the practical importance of power loss to the broader single ventricle physiology. To address this critical knowledge gap, this study leverages a large cohort from the National Institutes of Health-supported Georgia Tech-Children's Hospital of Philadelphia cardiac magnetic resonance (CMR) Fontan database for detailed CFD evaluation. These data also were used to establish population baselines for metrics of interest and draw generalizable correlations among them. 


$$
\begin{aligned}
& \text { Abbreviations and Acronyms } \\
& \text { BSA = body surface area } \\
& \text { CFD = computational fluid dynamics } \\
& \mathrm{CMR}=\text { cardiac magnetic resonance } \\
& \text { HFD = hepatic flow distribution } \\
& \text { iPL = indexed power loss } \\
& \text { IVC = inferior vena cava } \\
& \text { LPA }=\text { left pulmonary artery } \\
& \text { PC MRI = phase contrast magnetic resonance } \\
& \text { imaging } \\
& \mathrm{Q}_{\mathrm{s}} \quad=\text { systemic venous flow } \\
& \text { RPA = right pulmonary artery } \\
& \text { SVC = superior vena cava } \\
& \text { TCPC = total cavopulmonary connection } \\
& \text { WU }=\text { Wood units }
\end{aligned}
$$

We hypothesize that TCPC power loss varies considerably among connection types, such as extracardiac and intra-atrial Fontans (eg, connection geometry), and high losses may adversely affect systemic hemodynamics and ventricular function.

\section{MATERIALS AND METHODS}

This analysis was approved by the institutional review boards of the Children's Hospital of Philadelphia and Georgia Tech. Informed consent was obtained.

\section{Patients}

A total of 114 consecutive patients with a completed Fontan connection who underwent CMR between 2002 and 2012 were identified. Patients were excluded on the basis of severe CMR artifacts, lack of sufficient phase contrast data, or diagnosis of Ebstein's anomaly, reducing the number of investigated patients to 100. Demographic information is provided in Table 1.

\section{Anatomy and Velocity Reconstruction}

A transverse stack of static CMR images served as the basis of TCPC anatomic reconstruction. In-plane resolution was $1.18 \mathrm{~mm}^{2}$ on average (range, $0.55-1.88 \mathrm{~mm}$ ), and average through-plane resolution was $4 \mathrm{~mm}$ (range, 3-5 mm). The images were interpolated, ${ }^{15}$ segmented $^{16}$ in MATLAB (The Mathworks, Natick, Mass), and reconstructed into a 3-dimensional surface in Geomagic Studio (Geomagic, Inc, Research Triangle Park, NC). The Nakata Index ${ }^{17}$ was calculated using the mean pulmonary artery radii from the 3-dimensional reconstructions.

Single-slice phase contrast magnetic resonance imaging (PC MRI) was acquired in the ascending aorta, superior vena cava (SVC), inferior vena cava (IVC)/Fontan baffle, proximal left pulmonary artery (LPA) and right pulmonary artery (RPA), and persistent left SVC or azygos vein, when appropriate. These images were segmented semiautomatically to calculate vessel specific blood flow rates. Fenestration flow was estimated from the difference between systemic venous flow $\left(Q_{s}\right)$ and pulmonary arterial flows.

\section{Computational Fluid Dynamics}

Simulations were divided among several investigators and performed using a previously validated solver based on the immersed boundary method, ${ }^{18,19}$ in which the governing equations were solved in their complete unsteady formulation. The patient-specific models were fitted with a surface mesh in Gambit (ANSYS Inc, Lebanon, $\mathrm{NH}$ ) and registered within a fixed Cartesian grid. Grid spacing was generally set at $2 \%$ of the IVC inlet diameter to achieve mesh independence, ${ }^{19}$ producing a minimum of $371 \mathrm{k}$ nodes in the computational domain.

Because the primary CFD end point was a representative, time-averaged measure of power loss, simulations assumed time-averaged boundary conditions based on the PC MRI data for each vessel. At the inlets, a flat velocity profile was imposed. The presence of a fenestration was ignored. At the outlets, flow boundary conditions were imposed on the basis of the ratio of measured vessel flow to total pulmonary arterial flow. In a few cases when a stenosis was present in 1 branch pulmonary artery, the measured flow rate in the stenotic artery was retained for the simulation while flow through the contralateral branch pulmonary artery was assumed to be equal to the total caval return less the flow in the stenotic artery. Because the sum of the measured inflows usually exceeds the sum of the measured outflows (due in part to fenestration flow), imposing the measured pulmonary artery ratio would typically overestimate the measured arterial flows in the simulation. It is known that connection energetics can be dominated by localized pulmonary artery stenoses, ${ }^{20}$ so the practice described earlier prevented the artificial increase in imposed flow across the stenotic region. When the right upper lobe branch artery was retained in the computational domain, the measured RPA flow split (taken proximal to the branch) was divided between the lower and upper branches on the basis of the ratio of their respective areas.

The CFD outputs include the pulmonary distribution of IVC flow (assumed to be uniformly carrying hepatic flow distribution [HFD]), calculated via the flux distribution of IVC streamlines, and power loss according to the following:

$$
\text { PowerLoss }=\sum_{\text {inlets }} \int_{A}\left(p+\frac{1}{2} \rho v^{2}\right) v \cdot \mathrm{d} A-\sum_{\text {outlets }} \int_{A}\left(p+\frac{1}{2} \rho v^{2}\right) v \cdot \mathrm{d} A
$$

where $p$ is the static pressure, $\rho$ is density, A is vessel area, and $v$ is the velocity. Indexed power loss (iPL) was as follows ${ }^{21}$ :

$$
\frac{P L}{\rho Q_{s}^{3} / B S A^{2}}
$$

where $\mathrm{Q}_{\mathrm{s}}$ is the systemic venous flow $\left[\mathrm{L} \cdot \mathrm{s}^{-1}\right]$, and BSA is the body surface area. The pressure decrease across the connection was computed from power loss (where pressure decrease, $\Delta \mathrm{P}$, is related to power loss as: $\left.\triangle \mathrm{P}_{\mathrm{TCPC}}=\frac{P L}{Q_{s}}\right)$ to calculate the normalized connection resistance (Resistance $\left.=\frac{Q_{\triangle} P_{T C P C}}{Q_{s} / B S A}\right)$ in Wood units $(\mathrm{WU})\left(\mathrm{mm} \mathrm{Hg} \cdot \mathrm{min} \cdot \mathrm{L}^{-1} \cdot \mathrm{m}^{2}\right)$.

\section{Comparison of Time-Averaged and Pulsatile Boundary Conditions}

To quantify the effect of the selected (time-averaged) boundary conditions on power loss, a subset $(n=35)$ of cases also were simulated using time-varying boundary conditions. For these simulations, the cardiacgated PC MRI flow rates were directly imposed on the inlet vessels, whereas the outlet boundary conditions were based on the measured time-varying outflow distribution to enforce continuity of mass. Pulsatile power loss values from these simulations were compared with the paired results of the time-averaged simulations using a Bland-Altman analysis ${ }^{22}$ and the coefficient of variation (ratio of averaged pairwise standard deviations to the group mean).

\section{Four-Dimensional Phase Contrast Magnetic Resonance Imaging}

To further justify the modeling assumptions, simulation results and 4-dimensional PC MRI data interpolated with a divergence-free basis function were quantitatively and qualitatively compared for 6 patients: 3 with extracardiac and 3 with intra-atrial connections. ${ }^{11,23}$ Flow distribution from the 4-dimensional PC MRI data was quantified using the built-in temporal interpolation and particle tracking functionalities of ParaView (paraview.org) and compared with CFD data for the same patients. 
TABLE 1. Patient demographic details

\begin{tabular}{lc}
\hline Age $(\mathrm{y})$ & $12.0 \pm 6.8$ \\
$\mathrm{BSA}\left(\mathrm{m}^{2}\right)$ & $1.23 \pm 0.46$ \\
Nakata Index $\left(\mathrm{mm}^{2} / \mathrm{m}^{2}\right)$ & $219 \pm 89$ \\
Gender (male/female) & $55 / 45$ \\
Connection type (intra-atrial/extracardiac/atriopulmonary) & $64 / 33 / 3$ \\
HLHS vs non-HLHS & $31 / 69$ \\
Bilateral SVC connections & 15 \\
\hline
\end{tabular}

Data are reported as mean \pm standard deviation. $B S A$, Body surface area; $H L H S$, hypoplastic left heart syndrome; $S V C$, superior vena cava.

\section{Statistics}

Statistical analyses were performed using Minitab (Minitab Inc, State College, Pa). Continuous variables were tested for normality using the Anderson-Darling test. The Student $t$ test and Mann-Whitney test were used for comparisons between groups, as appropriate, and Pearson's correlation was used to identify relationships between variables. The analysis presented is exploratory in nature, and thus no adjustments were made for multiple comparisons.

\section{RESULTS}

\section{Computational Fluid Dynamics and Cardiac Magnetic Resonance Comparison}

Figures 1 and 2 show instantaneous velocity streamlines for the time-averaged CFD and representative time points from the phasic CMR results for 3 patients with extracardiac connection and 3 patients with intra-atrial connection, respectively. In patient $\mathrm{A}$, both modalities show that the caval flow collision favors SVC flow to the RPA, whereas
IVC flow was evenly split. For patient B, the SVC flow streams entirely to the LPA with noticeable flow acceleration through the subaortic section of the pulmonary artery. A distinct flow collision/stagnation point (Figure 1, arrow) is seen in the center of the connection for patient $\mathrm{C}$ with IVC flow favoring the LPA.

In Figure 2, the intra-atrial flows are marked by complex mixing and recirculation patterns. Some dynamic attributes are seen from the CMR (eg, the transient translation of the central vortex in patient $\mathrm{D}$ ) that are not entirely captured by the time-averaged CFD results; however, the general characteristics and overall velocity magnitudes are still conserved. For example, the SVC flow is constrained along the lateral right wall for all 3 patients (with large vortices forming in patients D and F) and primarily exits the RPA.

Comparison of the HFD results between modalities is provided in Figures 1 and 2. Differences ranged from 3\% to $16 \%$, with an average absolute difference of $11.8 \%$ and a coefficient of variation of $14 \%$.

\section{Time-Averaged Versus Pulsatile Boundary Conditions}

Figure 3 shows the Bland-Altman mean versus difference plot of time-averaged versus pulsatile boundary condition power losses. The $95 \%$ limits of agreement are denoted by the "2SD" lines. Pulsatile power loss was generally higher than time-averaged for a given patient, as indicated by the negative average difference. Despite this systematic

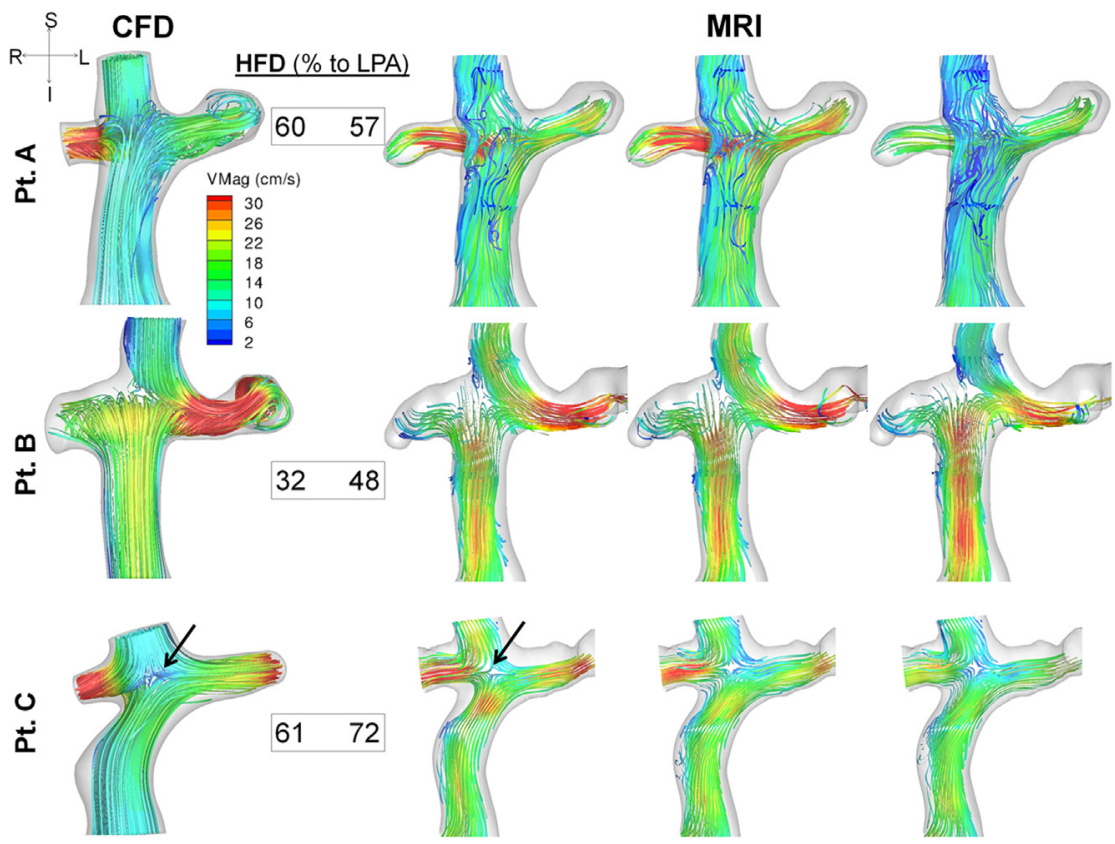

FIGURE 1. Three-dimensional velocity fields from time-averaged computational simulations (left) and representative phases from the CMR acquisitions (right) for 3 patients with an extracardiac connection. Comparison of hepatic distribution results (as \% $\mathrm{LPA}$ ) shown for each case. Arrow for patient $\mathrm{C}$ highlights a conserved region of flow stagnation at the caval flow collision site. CFD, Computational fluid dynamics; HFD, hepatic flow distribution; $L P A$, left pulmonary artery; MRI, magnetic resonance imaging; Pt., patient. 


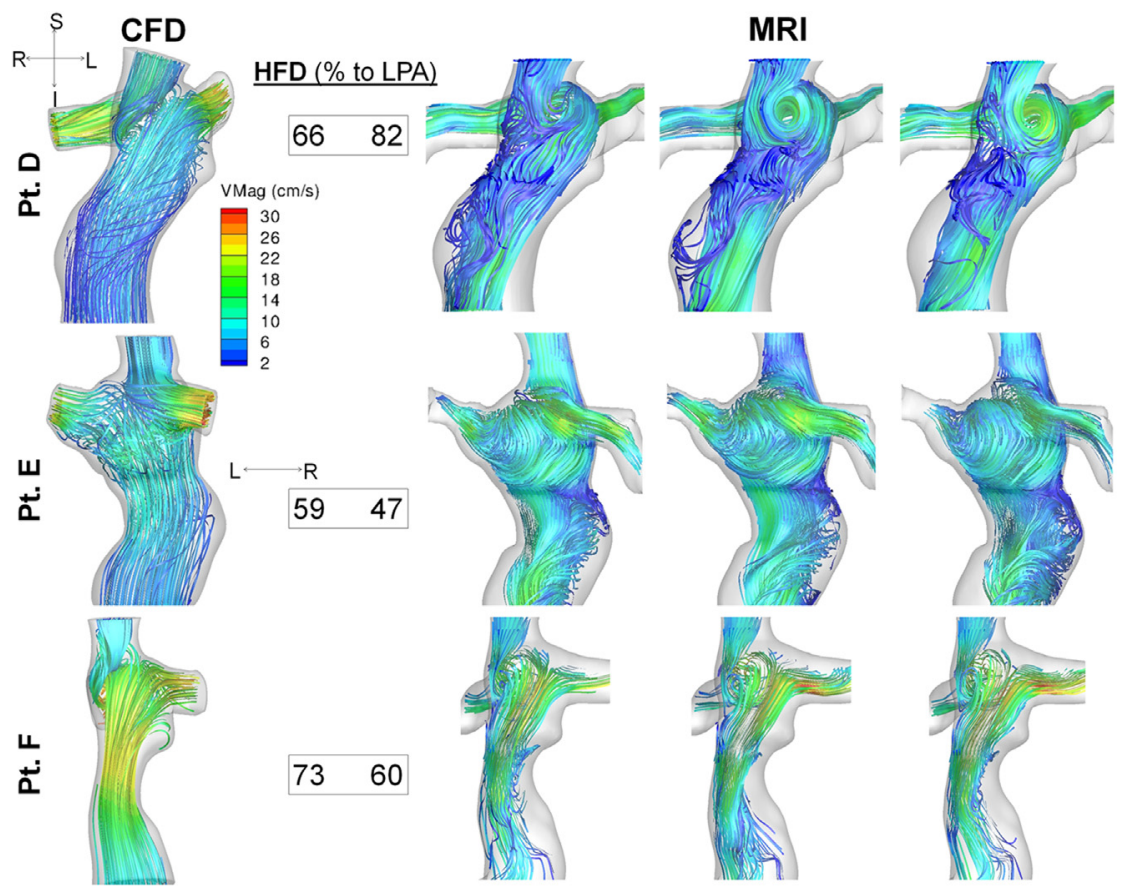

FIGURE 2. Three-dimensional velocity fields between time-averaged computational simulations (left) and representative phases from the CMR acquisitions (right) for 3 patients with an intra-atrial connection. Comparison of hepatic distribution results (as \%LPA) shown for each case. $C F D$, Computational fluid dynamics; HFD, hepatic flow distribution; LPA, left pulmonary artery; MRI, magnetic resonance imaging; $P t$., patient.

bias, the variation in these differences was small compared with the mean power loss values, with a coefficient of variation of $11 \%$.

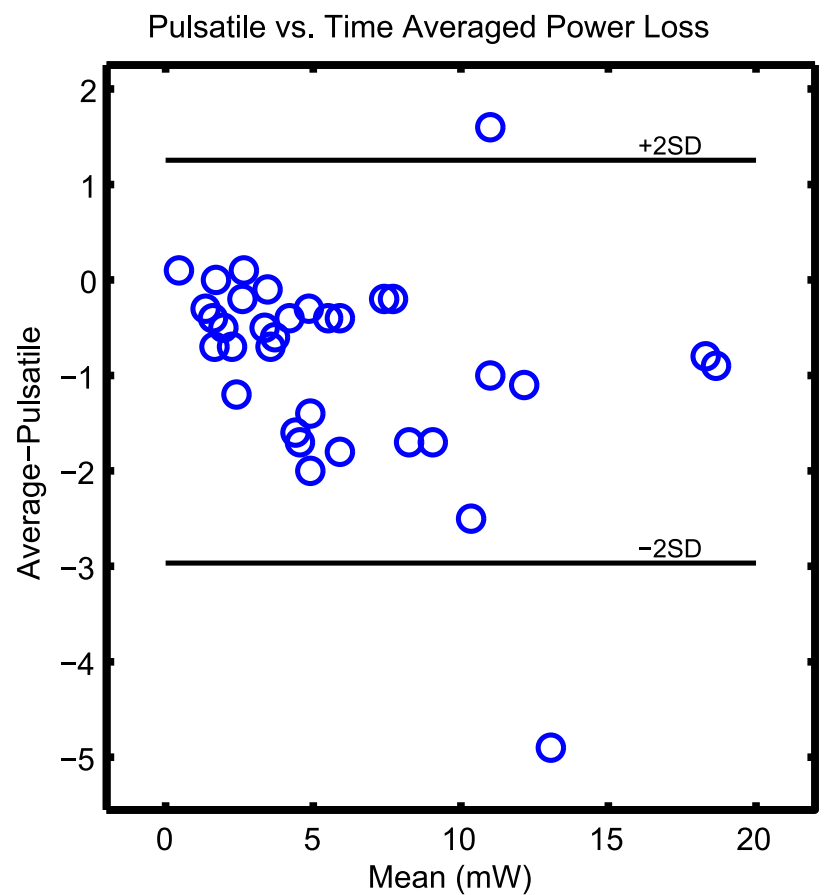

FIGURE 3. Bland-Altman mean versus difference comparison of power losses derived from simulations using pulsatile and time-averaged boundary conditions. The $95 \%$ confidence intervals are small compared with average power losses.

\section{Cohort Results}

Flow data derived from the through-plane PC MRI acquisitions and normalized to body surface area (BSA) are summarized in Table 2. On average, fenestration flow was less than $10 \%$ of Qs.

Hemodynamic findings from the CFD analysis are presented in Table 3. Mean HFD was $44 \%$ (to the LPA), and it correlated with the average pulmonary flow distribution of $45 \%$ to the LPA $(r=0.36, P<.001$; Figure $4, A)$. Additional correlations included BSA with both resistance and iPL ( $r=0.28$ and 0.37 , respectively; $P<.05$; Figure $4, B$ ) and age with both cardiac index and iPL $(r=-0.37$ and 0.26 , respectively; $P<.05$ ). After correcting for the presence of flow in the power loss indexing scheme with partial correlation, the natural logarithm of iPL was significantly correlated with both $\mathrm{Q}_{\mathrm{s}}(r=-0.31, P=.001$; Figure 4, $C)$

TABLE 2. Average flow data $\left(\mathrm{L} / \mathrm{min} / \mathrm{m}^{2}\right)$ by vessel from phase contrast magnetic resonance imaging

\begin{tabular}{lr}
\hline IVC & $1.72 \pm 0.55$ \\
SVC & $1.00 \pm 0.53$ \\
LSVC* & $0.64 \pm 0.35$ \\
Azygos vein* & $0.92 \pm 0.37$ \\
LPA & $1.21 \pm 0.63$ \\
RPA & $1.38 \pm 0.50$ \\
Fenestration $\dagger$ & $0.30 \pm 0.54$ \\
\hline Data are reported as mean \pm standard deviation. $I V C$, Inferior vena cava; $L P A$, left \\
pulmonary artery; $L S V C$, left superior vena cava; $R P A$, right pulmonary artery; \\
SVC, superior vena cava. *Not applicable to all patients. $\dagger$ Not measured for all \\
patients.
\end{tabular}


TABLE 3. Cohort hemodynamic results

\begin{tabular}{|c|c|c|c|c|c|c|}
\hline & $\begin{array}{c}\text { Cardiac index } \\
\left(\mathrm{L} / \mathrm{min} / \mathbf{m}^{2}\right) \\
\end{array}$ & $\mathrm{Q}_{\mathrm{s}}\left(\mathrm{L} / \mathrm{min} / \mathrm{m}^{2}\right)$ & $\begin{array}{l}\text { Pulmonary flow distribution } \\
(\% \text { LPA })\end{array}$ & HFD ( $\%$ LPA $)$ & Resistance (WU) & iPL \\
\hline Mean & 3.47 & 2.89 & 45 & 44 & 0.23 & 0.037 \\
\hline SD & 1.11 & 0.81 & 12 & 21 & 0.17 & 0.028 \\
\hline Median & 3.43 & 2.85 & 43 & 44 & 0.19 & 0.031 \\
\hline 25th percentile & 2.86 & 2.33 & 37 & 31 & 0.10 & 0.016 \\
\hline 75th percentile & 3.85 & 3.36 & 52 & 57 & 0.28 & 0.047 \\
\hline
\end{tabular}

$H F D$, Hepatic flow distribution; $i P L$, indexed power loss; $L P A$, left pulmonary artery; $Q_{s}$, systemic venous flow; $S D$, standard deviation; $W U$, Wood units.

and cardiac index $(r=-0.21, P=.04)$. Finally, the Nakata Index had a power law fit to both iPL $(r=-0.52, P<.001)$ and connection resistance $(r=-0.43, P<.001)$.

\section{Intra-Atrial Versus Extracardiac Connections}

In this comparison (neglecting 3 atriopulmonary connections), patients with intra-atrial connection were significantly older and had larger BSA, whereas there was a strong trend $(P=.07)$ toward a higher cardiac index in patients with extracardiac connection (Table 4). There were no statistical differences in resistance or iPL between groups $(P=.48$ and .24 , respectively). The pulmonary flow distribution to the LPA was significantly higher in extracardiac connections, but there was a trend toward lower HFD to the LPA $(P=.08)$ in those connections.

\section{Highest Versus Lowest Power Loss Connections}

Table 5 compares the characteristics and hemodynamics of the 5 highest and 5 lowest power loss (iPL) connections. The highest loss cases, although being older and having a
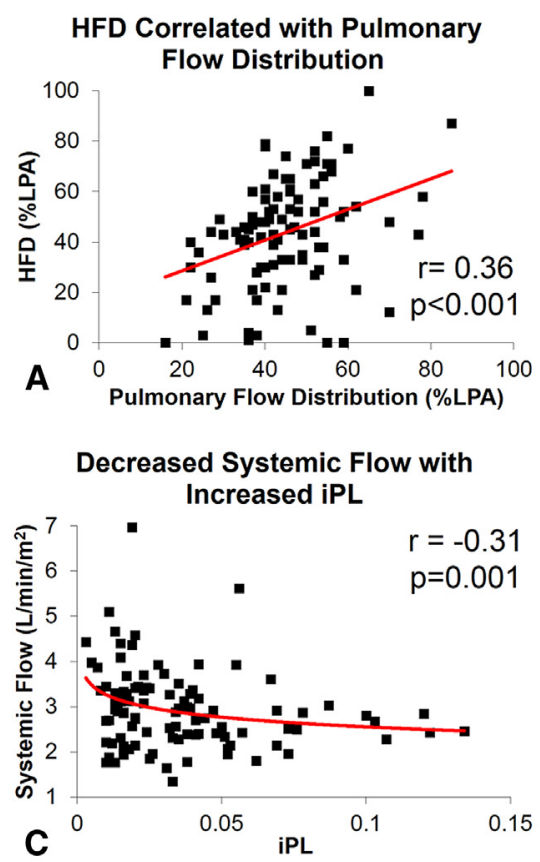

higher BSA, all had energetic measures at least 1 order of magnitude larger (ie, more dissipative) than the lowest loss ones. Qs and cardiac indices also were notably lower. Finally, the composition of the highest loss group with respect to connection type is notable because 3 of the 5 intra-atrial connections were baffle conduits (ie, not intraatrial lateral tunnel connections).

Figure 5 shows 3-dimensional velocity streamlines for the 5 highest power loss connections. In all cases, appreciable narrowing of the Fontan pathway to varying degrees created local acceleration, pressure decrease, and recirculation within the connections. Figure 6 shows a similar 3-dimensional velocity streamline analysis of the lowest power loss connections, which had lower maximal velocities and more ordered flow patterns than in Figure 5.

\section{DISCUSSION}

Fontan Power Loss and the Single Ventricle

TCPC design is one of the factors amenable to interventional/surgical manipulation in the care of patients with
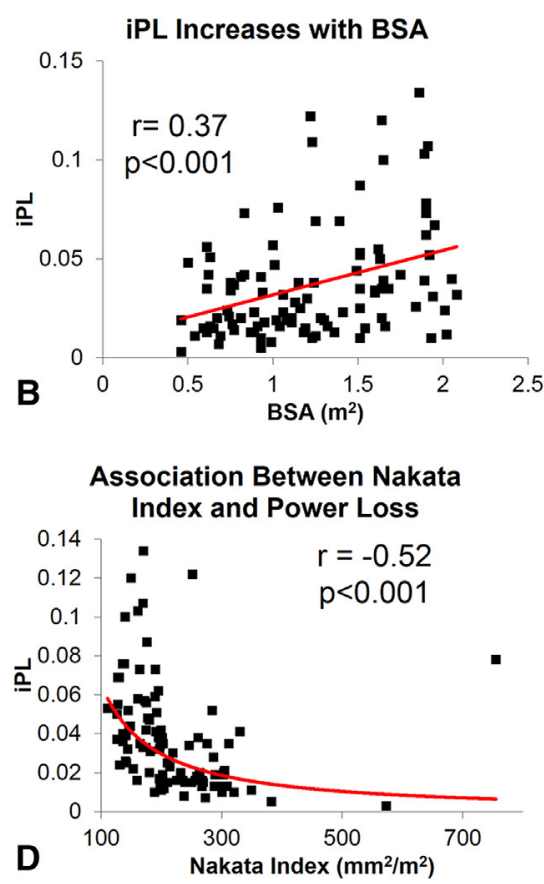

FIGURE 4. Statistically significant correlations observed between HFD and total pulmonary flow distribution (A): iPL and BSA (B), iPL and QS (C), and iPL and Nakata Index (D). BSA, Body surface area; $H F D$, hepatic flow distribution; $i P L$, indexed power loss; $L P A$, left pulmonary artery. 
TABLE 4. Comparison of intra-atrial and extracardiac connections

\begin{tabular}{lccc}
\hline & $\begin{array}{c}\text { Intra-atrial } \\
(\mathbf{N}=\mathbf{6 4})\end{array}$ & $\begin{array}{c}\text { Extracardiac } \\
(\mathbf{N}=\mathbf{3 3})\end{array}$ & $\boldsymbol{P}$ value \\
\hline Age $(\mathrm{y})$ & $13.5 \pm 6.5$ & $7.9 \pm 4.8$ & $<.001$ \\
BSA $\left(\mathrm{m}^{2}\right)$ & $1.33 \pm 0.43$ & $0.96 \pm 0.37$ & $<.001$ \\
Nakata Index $\left(\mathrm{mm}^{2} / \mathrm{m}^{2}\right)$ & $219 \pm 78$ & $206 \pm 58$ & .40 \\
Cardiac index $\left(\mathrm{L} / \mathrm{min}^{2} / \mathrm{m}^{2}\right)$ & $3.30 \pm 0.87$ & $3.90 \pm 1.41$ & .07 \\
$\mathrm{Q}_{\mathrm{s}}\left(\mathrm{L} / \mathrm{min} / \mathrm{m}^{2}\right)$ & $2.89 \pm 0.89$ & $3.10 \pm 0.91$ & .33 \\
Pulmonary distribution & $41 \pm 9$ & $51 \pm 15$ & .001 \\
$\quad(\% \mathrm{LPA})$ & & & \\
HFD $(\% \mathrm{LPA})$ & $46 \pm 18$ & $37 \pm 26$ & .08 \\
Resistance $(\mathrm{WU})$ & $0.25 \pm 0.19$ & $0.20 \pm 0.12$ & .48 \\
iPL & $0.040 \pm 0.031$ & $0.030 \pm 0.017$ & .24 \\
\hline
\end{tabular}

Mean \pm standard deviation. $B S A$, Body surface area; $H F D$, hepatic flow distribution; $i P L$, indexed power loss; $L P A$, left pulmonary artery; $Q_{s}$, systemic venous flow; $W U$, Wood units.

single ventricles. These data demonstrate that this patientto-patient variation led to a 2 orders of magnitude range in iPL, so elucidating its relationship to patient functional status and outcomes is of significant clinical relevance.

The mean TCPC resistance value from this cohort was $0.23 \mathrm{WU}$, compared with 1.3 to $1.8 \mathrm{WU}$ for normal pulmonary vascular resistances in patients undergoing the Fon$\tan ,{ }^{24,25}$ so these data indicate that the TCPC adds $15 \%$ to $20 \%$ on average to post-hepatic resistance. The significant inverse relationships of iPL with $\mathrm{Q}_{\mathrm{s}}$ and cardiac index suggest these losses have a relevant effect on cardiac function, particularly when elevated. These results are similar to the linear correlation between TCPC resistance and cardiac index reported previously. ${ }^{25}$

A physiology-based model of ventricular filling (ie, diastolic function) and cardiac output shows that resistance elements downstream of vascular capacitance have a drastic effect on limiting the ability of the ventricle to fill and thus provide adequate output. ${ }^{26}$ In the Fontan physiology/ circulation, the TCPC and pulmonary vasculature are 2 such critical resistive elements. Thus, a possible mechanism for the present findings is that elevated power loss resulting from suboptimal connection geometry contributes to

TABLE 5. Comparison of highest and lowest power loss total cavopulmonary connections

\begin{tabular}{lcc}
\hline & 5 most efficient & 5 least efficient \\
\hline Age $(\mathrm{y})$ & $9.2 \pm 4.9$ & $16.6 \pm 3.8$ \\
BSA $\left(\mathrm{m}^{2}\right)$ & $0.91 \pm 0.39$ & $1.70 \pm 0.29$ \\
Nakata Index $\left(\mathrm{mm}^{2} / \mathrm{m}^{2}\right)$ & $357 \pm 132$ & $180 \pm 41$ \\
Connection type (intra-atrial/ & $4 / 1 / 0$ & $5 / 0 / 0$ \\
$\quad$ extracardiac/atriopulmonary) & & \\
Cardiac index $\left(\mathrm{L} / \mathrm{min} / \mathrm{m}^{2}\right)$ & $3.89 \pm 0.64$ & $3.33 \pm 0.66$ \\
$\mathrm{Q}_{\mathrm{s}}\left(\mathrm{L} / \mathrm{min} / \mathrm{m}^{2}\right)$ & $3.57 \pm 0.85$ & $2.54 \pm 0.22$ \\
Resistance $(\mathrm{WU})$ & $0.05 \pm 0.01$ & $0.66 \pm 0.09$ \\
iPL & $0.007 \pm 0.003$ & $0.117 \pm 0.012$ \\
\hline
\end{tabular}

Mean \pm standard deviation. $B S A$, Body surface area; $i P L$, indexed power loss; $Q_{s}$, systemic venous flow; $W U$, Wood units. restricted preload and preload reserve ${ }^{27,28}$ of the single ventricle, which may limit efficient long-term performance.

\section{Extracardiac Versus Intra-Atrial Connections}

Extracardiac connections had a strong trend $(P=.08)$ toward lower HFD to the LPA compared with intra-atrial connections ( $38 \%$ vs $47 \%$, respectively), despite significantly higher total LPA flow percentage in extracardiac connections $(51 \%$ vs $41 \%)$. A recent study found that HFD correlated with the total pulmonary distribution in intra-atrial connections because of caval mixing within the connection. Conversely, HFD in extracardiac connections have been reported to correlate only with caval offset. ${ }^{29}$ These observations agree well with the present findings. Although HFD did correlate with the total flow distribution for extracardiacs in this analysis, the significant influence of caval offset was still apparent because more than $60 \%$ of IVC flow perfused the RPA (the predominant direction of caval offsetting for such connections) despite a nearly balanced total distribution (51\% LPA). Most important, neither result suggests an inherent risk factor for unilateral hepatic distribution and pulmonary arteriovenous malformations. ${ }^{30}$

The more relevant comparison is in regard to the comparative resistance of the 2 approaches because the superiority of one approach over the other has been the subject of debate for a number of years. ${ }^{31-34}$ In this series, there were no differences in power loss between the connection types.

The question then remains as to what distinguishes between hemodynamically favorable and unfavorable connections. The importance of pulmonary artery size has been well documented, ${ }^{7,20}$ and the large difference in the average Nakata indices between the most and least efficient groups provides strong support for its prominence. In addition, the effect of local constriction/ undersizing of the Fontan pathway also was apparent from the present data. The worst performing connections were characterized by the presence of high-velocity Fontan flow immediately proximal to the cavopulmonary connection that created large separated flow regions and vortices within the junction (Figure 5). The combination of multiple suboptimal geometric features (eg, stenosis, sharp bends, sudden expansions) in some cases further compounded these inefficiencies. As a result, the iPL in those cases was 3 times greater than the cohort mean. Furthermore, these hemodynamics are likely to be significantly exacerbated under higher cardiac output conditions, and could thus contribute to poor exercise tolerance. ${ }^{5}$ In 2 of the cases (L2, L5), lateral tunnel stenosis was present and contributed to these adverse hemodynamics, whereas a small intra-atrial conduit was a problem for 3 patients (L1, L3, L4). On the basis of the present cohort, such adverse geometric characteristics are rare but seem to warrant attention (eg, via stenting the lateral tunnel pathway) when observed clinically. 


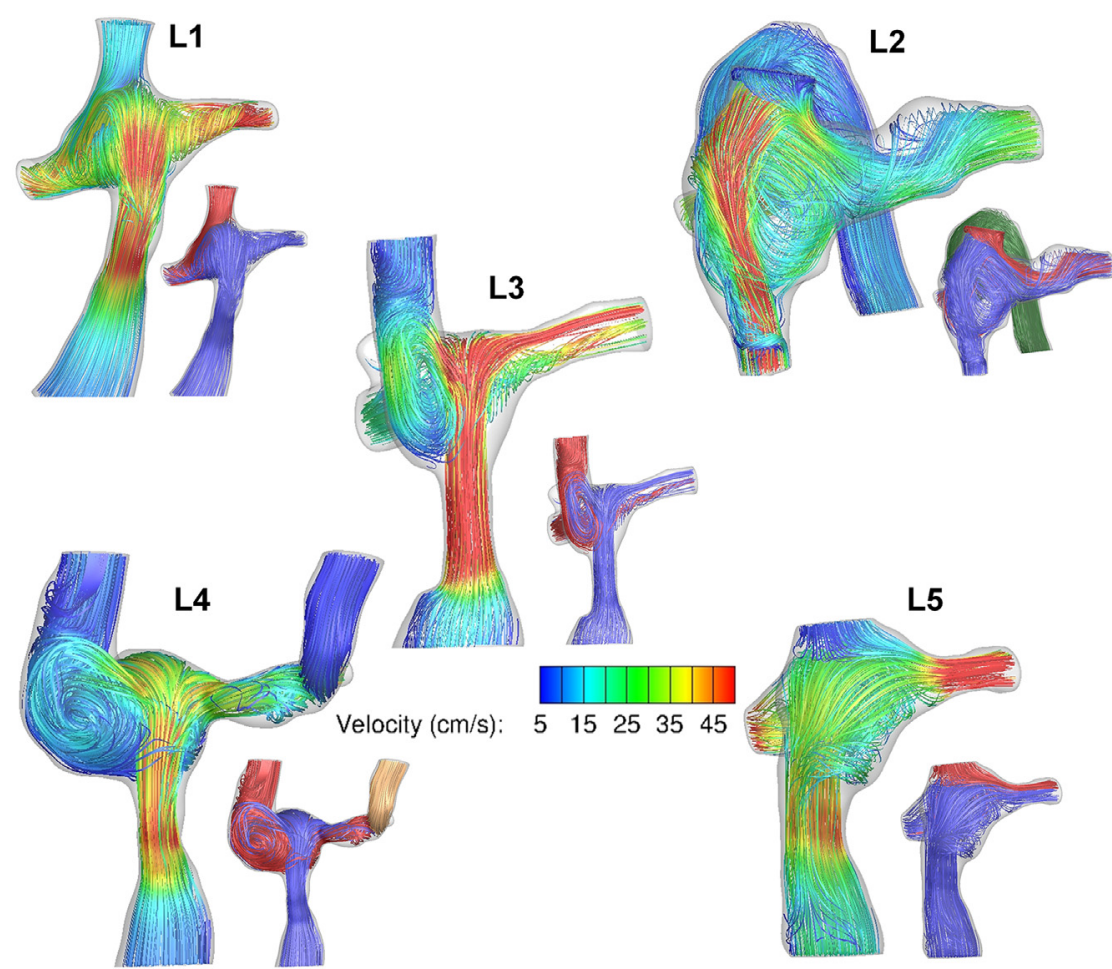

FIGURE 5. Three-dimensional velocity streamlines color coded by local velocity magnitude and vessel of origin (inset images: blue, IVC; red, SVC) for the 5 highest iPL connections.

\section{Four-Dimensional Phase Contrast Magnetic Resonance Imaging and Computational Fluid Dynamics in Fontan Evaluation}

This study used both 4-dimensional PC MRI and CFD to characterize Fontan hemodynamics; advancements in both technologies have increased the frequency of their use for such applications, ${ }^{9,11,12,35}$ yet few, if any, studies have provided a direct comparison of their results in the TCPC or any other vascular region. The primary findings from this comparison were quantitative similarities in HFD measures and qualitative similarities in the 3-dimensional flow fields between modalities, which support the accuracy of the CFD simulations.

Furthermore, although there are considerable areas of overlap in the knowledge gained from these modalities, there are important distinctions that should be noted that made imaging-based CFD a unique and important asset in this analysis. The first point is the availability of large datasets: The CFD protocol used requires basic imaging inputs, which allowed for the use of retrospective data to be used in generating a large patient sample. By comparison, 4-dimensional PC MRI is only recently gaining in popularity and is still not a part of routine clinical protocols; a study of this size based solely on 4-dimensional PC MRI analyses is still several years away. Assessing power loss is another strength of CFD because of the different spatial resolution characteristics of the 2 modalities: Fontan 4-dimensional PC MRI studies have reported voxel sizes ranging from 5.8 to $17.5 \mathrm{~mm}^{3},{ }^{11,12}$ whereas the grid size for the solver in our study was on the order of $0.05 \mathrm{~mm}^{3}$. These differences have significant implications for the ability of each method to resolve velocities close to vessel boundaries and accurately evaluate spatial derivatives of the velocity fields, both of which are crucial for hemodynamic power loss evaluation. Finally, there are technical considerations related to the acquisition of CMR and the potential for cycle averaging, noise, finite velocity measurement resolution, and turbulent de-phasing to affect measurement fidelity. CFD has its own limitations, as discussed next, but an accurate computational result clearly provides a superior means of quantitative analysis of the velocity field. Moving forward, both techniques will play critical, complementary roles in further understanding this complex physiology.

\section{Study Limitations}

The simulations were all performed with the assumptions of time-averaged flow conditions and rigid vessel walls. Figure 3 indicates that the time-averaged flow assumption introduced a small quantitative bias in the power loss results compared with simulations assuming pulsatile flow boundary conditions and rigid walls (which is generally considered to be the current state-of-the-art). However, on the basis of the constrained limits of agreement and the low 

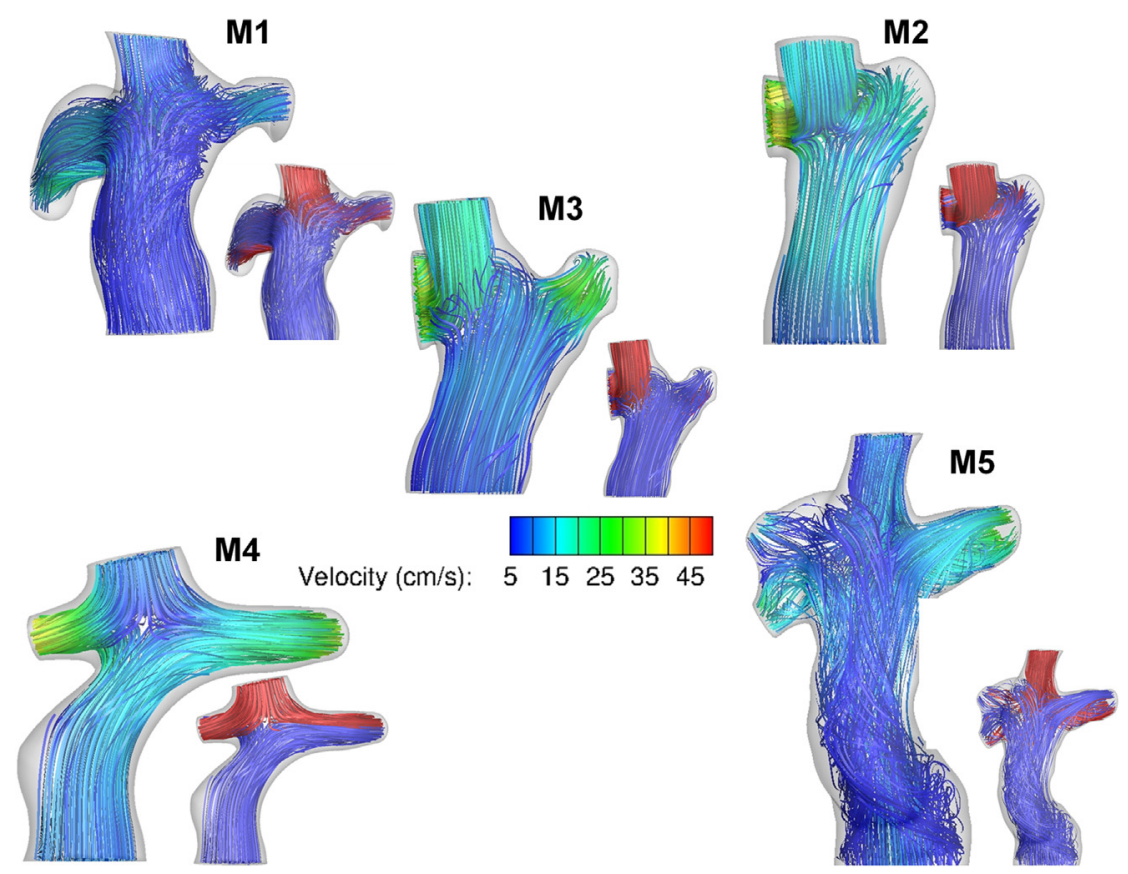

FIGURE 6. Three-dimensional velocity streamlines color coded by local velocity magnitude and vessel of origin (inset images: blue, IVC; red, SVC) for the 5 lowest iPL connections.

coefficient of variation, the effect of the time-averaged flow assumption on power loss was small and acceptable for quantification of this time-averaged end point. Moreover, the quantitative consistency and qualitative similarities between the CFD and 4-dimensional PC MRI data provide similar assurance that despite the simplifying assumptions made, the simulated results presented are reasonable representations of the in vivo dynamics. Spatial resolution limitations in the imaging technique can have negative effects on the fidelity of reconstructed vessel sizes, particularly by exaggerating the severity of stenotic PAs. However, the techniques used for image interpolation and segmentation have been rigorously validated against phantoms, ${ }^{15}$ so we are confident in the overall accuracy of these models.

Fenestration flow was systematically ignored, which is a limitation of the retrospective data analysis. However, because fenestration flow accounted for less than $10 \%$ of systemic flow on average, that assumption was acceptable.

There was a significant difference in age between the extracardiac and intra-atrial groups, which presents a challenge in making direct comparisons. However, the observed association between age and iPL was weak and positive, suggesting that as the patients in the extracardiac group (younger group) age, their average iPL may increase toward the current average of the intra-atrial group from this cohort. Thus, it is unlikely that the finding of no difference between groups is affected by this age discrepancy.

Finally, the approach to the Fontan connection can vary considerably from center to center and surgeon to surgeon. Although this is a single-center experience, the present findings comparing intra-atrial and extracardiac connections may be globally applicable because there are no specific practices at this center that would create a significant distinction with the broader approach to Fontan surgery.

\section{CONCLUSIONS}

Congenital heart disease occurs in $1 \%$ of the population, and single ventricle defects make up a smaller subset; the ability to acquire and analyze large patient data samples is a unique challenge and significant accomplishment. From this largest computational analysis of the Fontan connection to date, several clinically relevant insights were gained. First, power loss varies widely among patients with Fontan and may vary with age and development. Second, there is an inverse correlation between indexed TCPC power loss and $\mathrm{Q}_{\mathrm{s}}$, which supports the hypothesis that TCPC hemodynamics can negatively affect ventricular filling and preload. Third, no energetic differences were observed between intra-atrial and extracardiac Fontan connections, but the presence of undersized pulmonary arteries or Fontan pathway stenosis did have a detrimental effect on power loss.

\section{References}

1. Fontan F, Baudet E. Surgical repair of tricuspid atresia. Thorax. 1971;26:240-8.

2. Gaynor JW, Bridges ND, Cohen MI, Mahle WT, Decampli WM, Steven JM, et al. Predictors of outcome after the Fontan operation: is hypoplastic left heart syndrome still a risk factor? J Thorac Cardiovasc Surg. 2002;123:237-45.

3. Gersony DR, Gersony WM. Management of the postoperative Fontan patient. Prog Pediatr Cardiol. 2003;17:73-9.

4. de Leval MR. The Fontan circulation: what have we learned? what to expect? Pediatr Cardiol. 1998;19:316-20. 
5. Whitehead KK, Pekkan K, Kitajima HD, Paridon SM, Yoganathan AP, Fogel MA. Nonlinear power loss during exercise in single-ventricle patients after the Fontan: insights from computational fluid dynamics. Circulation. 2007; 116(11 Suppl):I165-71.

6. DeGroff CG. Modeling the Fontan circulation: where we are and where we need to go. Pediatr Cardiol. 2008;29:3-12

7. Pekkan K, Kitajima HD, de Zelicourt D, Forbess JM, Parks WJ, Fogel MA, et al. Total cavopulmonary connection flow with functional left pulmonary artery stenosis: angioplasty and fenestration in vitro. Circulation. 2005;112:3264-71.

8. Marsden AL, Vignon-Clementel IE, Chan FP, Feinstein JA, Taylor CA. Effects of exercise and respiration on hemodynamic efficiency in CFD simulations of the total cavopulmonary connection. Ann Biomed Eng. 2007;35:250-63.

9. Marsden AL, Bernstein AJ, Reddy VM, Shadden SC, Spilker RL, Chan FP, et al. Evaluation of a novel Y-shaped extracardiac Fontan baffle using computational fluid dynamics. J Thorac Cardiovasc Surg. 2009;137:394-403.

10. Haggerty CM, Kanter KR, Restrepo M, de Zélicourt DA, Parks WJ, Rossignac J, et al. Simulating hemodynamics of the Fontan Y-graft based on patient-specific in vivo connections. J Thorac Cardiovasc Surg. 2013;145:663-70.

11. Sundareswaran KS, Haggerty CM, de Zelicourt D, Dasi LP, Pekkan K, Frakes DH, et al. Visualization of flow structures in Fontan patients using three-dimensional phase contrast magnetic resonance imaging. J Thorac Cardiovasc Surg. 2012;143:1108-16.

12. Markl M, Geiger J, Kilner PJ, Föll D, Stiller B, Beyersdorf F, et al. Time-resolved three-dimensional magnetic resonance velocity mapping of cardiovascular flow paths in volunteers and patients with Fontan circulation. Eur J Cardiothorac Surg. 2011;39:206-12.

13. Sharma S, Goudy S, Walker P, Panchal S, Ensley A, Kanter K, et al. In vitro flow experiments for determination of optimal geometry of total cavopulmonary connection for surgical repair of children with functional single ventricle. $J$ Am Coll Cardiol. 1996;27:1264-9.

14. Hsia T-Y, Migliavacca F, Pittaccio S, Radaelli A, Dubini G, Pennati G, et al. Computational fluid dynamic study of flow optimization in realistic models of the total cavopulmonary connections. J Surg Res. 2004;116:305-13.

15. Frakes D, Conrad C, Healy T, Monaco JW, Fogel M, Sharma S, et al. Application of an adaptive control grid interpolation technique to morphological vascular reconstruction. IEEE Trans Biomed Eng. 2003;50:197-206.

16. Frakes DH, Smith MJ, Parks WJ, Sharma S, Fogel MA, Yoganathan AP. New techniques for the reconstruction of complex vascular anatomies from MRI images. J Cardiovasc Magn Reson. 2005;7:425-32.

17. Nakata S, Imai Y, Takanashi Y, Kurosawa H, Tezuka K, Nakazawa M, et al. A new method for the quantitative standardization of cross-sectional areas of the pulmonary arteries in congenital heart diseases with decreased pulmonary blood flow. J Thorac Cardiovasc Surg. 1984;88:610-9.

18. Ge L, Sotiropoulos F. A numerical method for solving the $3 \mathrm{~d}$ unsteady incompressible Navier-Stokes equations in curvilinear domains with complex immersed boundaries. J Comput Phys. 2007;225:1782-809.

19. de Zélicourt D, Ge L, Wang C, Sotiropoulos F, Gilmanov A, Yoganathan AP. Flow Simulations in arbitrarily complex cardiovascular anatomies - an unstructured Cartesian grid approach. Comput Fluids. 2009;38:1749-62.
20. Dasi LP, Krishnankutty R, Kitajima H, Pekkan K, Sundareswaran KS, Fogel M, et al. Fontan hemodynamics: importance of pulmonary artery diameter. J Thorac Cardiovasc Surg. 2009;137:560-4.

21. Dasi LP, Pekkan K, de Zelicourt D, Sundareswaran KS, Krishnankutty R, Delnido PJ, et al. Hemodynamic energy dissipation in the cardiovascular system: generalized theoretical analysis on disease states. Ann Biomed Eng. 2009;37: 661-73.

22. Bland JM, Altman D. Statistical methods for assessing agreement between two methods of clinical measurement. Lancet. 1986;327:307-10.

23. Sundareswaran K, de Zélicourt D, Sharma S, Kanter KR, Spray TL, Rossignac J, et al. Correction of pulmonary arteriovenous malformation using image based surgical planning. JACC Cardiovasc Imaging. 2009;2:1024-30.

24. Khairy P, Fernandes SM, Mayer JE, Triedman JK, Walsh EP, Lock JE, et al Long-term survival, modes of death, and predictors of mortality in patients with Fontan surgery. Circulation. 2008;295:H2427-35.

25. Sundareswaran KS, Pekkan K, Dasi LP, Whitehead K, Sharma S, Kanter KR et al. The total cavopulmonary connection resistance: a significant impact on single ventricle hemodynamics at rest and exercise. Am J Physiol Heart Circ Physiol. 2008;295:H2427-35.

26. Guyton A, Abernathy B, Langston J, Kaufmann B, Fairchild H. Relative importance of venous and arterial resistances in controlling venous return and cardiac output. Am J Physiol. 1959;196:1008-14.

27. Senzaki H, Masutani S, Ishido H, Taketazu M, Kobayashi T, Sasaki N, et al. Cardiac rest and reserve function in patients with Fontan circulation. J Am Coll Car diol. 2006; 47:2528-35.

28. Gewillig M, Brown SC, Eyskens B, Heying R, Ganame J, Budts W, et al. The Fontan circulation: who controls cardiac output? Interact Cardiovasc Thorac Surg. 2010;10:428-33.

29. Dasi LP, Whitehead K, Pekkan K, de Zelicourt D, Sundareswaran K, Kanter K, et al. Pulmonary hepatic flow distribution in total cavopulmonary connections: extracardiac versus intracardiac. J Thorac Cardiovasc Surg. 2011;141:207-14.

30. Duncan B, Desai S. Pulmonary arteriovenous malformations after cavopulmonary anastomosis. Ann Thorac Surg. 2003;76:1759-66.

31. Fiore AC, Turrentine M, Rodefeld M, Vijay P, Schwartz TL, Virgo KS, et al. Fontan operation: a comparison of lateral tunnel with extracardiac conduit. Ann Thorac Surg. 2007;83:622-30.

32. Lardo AC, Webber S, Friehs I, del Nido P, Cape EG. Fluid dynamic comparison of intra-atrial and extracardiac total cavopulmonary connections. J Thorac Cardiovasc Surg. 1999;117:697-704.

33. Migliavacca F, Dubini G, Bove EL, de Leval MR. Computational fluid dynamics simulations in realistic 3-D geometries of the total cavopulmonary anastomosis: the influence of the inferior caval anastomosis. J Biomech Eng. 2003;125:805-13.

34. Kumar SP, Rubinstein CS, Simsic JM, Taylor AB, Saul JP, Bradley SM. Latera tunnel versus extracardiac conduit Fontan procedure: a concurrent comparison. Ann Thorac Surg. 2003;76:1389-97.

35. Haggerty CM, de Zelicourt D, Restrepo M, Rossignac J, Spray TL, Kanter KR et al. Comparing pre- and post-operative Fontan hemodynamic simulations: implications for the reliability of surgical planning. Ann Biomed Eng. 2012;40 2639-51. 